\section{Crenças de professores sobre o uso do dicionário escolar: uma abordagem contextual}

\author{
Teachers' beliefs about the \\ use of learner's dictionary: a \\ contextual approach
}

Luan Talles de Araújo BRITO (IFRN) luan.brito@ifrn.edu.br

Recebido em: 20 de set. de 2020. Aceito em: 14 de out. de 2020.

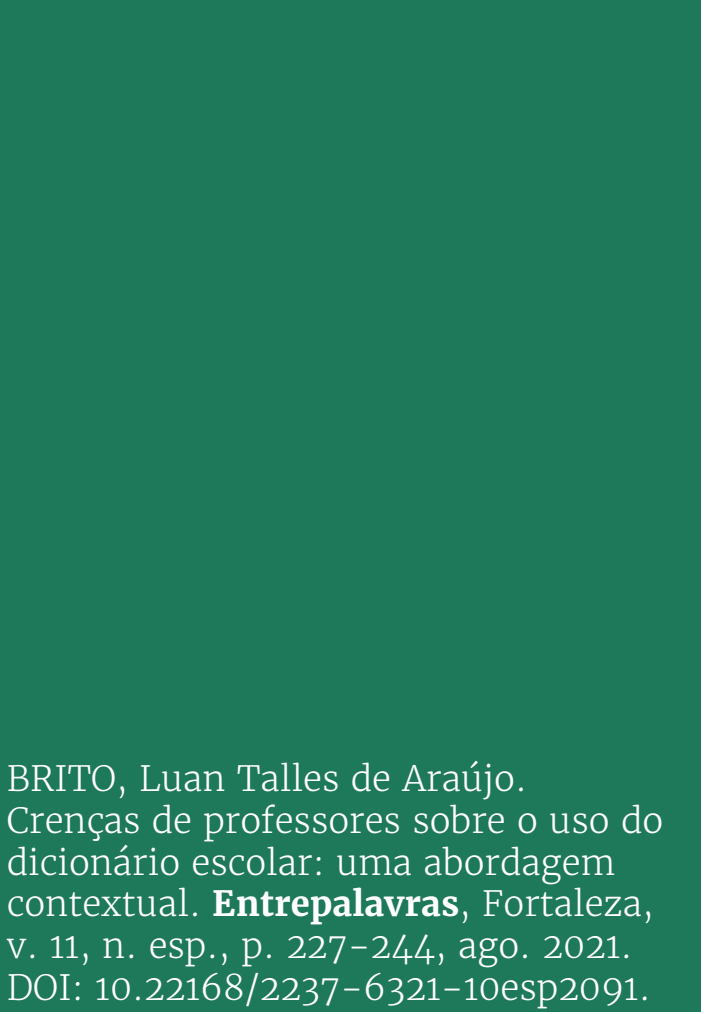

Resumo: O presente artigo advém de uma pesquisa de campo motivada pelo objetivo de analisar as crenças de professores sobre o uso do dicionário escolar e suas relações com o comportamento desses sujeitos. Para tanto, os dados analisados procedem de observações de aulas e entrevistas semiestruturadas com dois professores de $5^{\circ}$ ano do ensino fundamental de uma escola pública municipal de Brejo do Cruz - Paraíba. No referencial teórico, destacam-se os estudos de crenças na área de ensino e aprendizagem de línguas, desenvolvidos por Richardson (1996), Barcelos (2001, 2006) e Bonfim e Conceição (2009), além de alguns trabalhos do campo da Metalexicografia Pedagógica, como Pontes e Santiago (2009), Coroa (2011), Corrêa (2011) e Bolzan (2012). A análise indica que os professores acreditam que o contexto influencia o sentido da palavra pesquisada no dicionário e que o uso desse material didático auxilia na produção textual, além de estarem atentos para aspectos composicionais da obra dicionarista. Por conseguinte, os resultados revelam que as crenças dos sujeitos investigados ora influenciam, ora vão de encontro às suas práticas pedagógicas, sendo constatado, ainda, o 
v. 11 (esp.)

$227-244$ ago. 2021

fato de que a autorreflexão sobre a experiência docente serve para reforçar a adesão a determinada posição valorativa.

Palavras-chave: Crenças de professores. Dicionário escolar. Práticas pedagógicas.

Abstract: The present article is the result of a field research motivated by the objective of analyzing teachers' beliefs about the use of learner's dictionary and its relations with the behavior of these subjects. For this purpose, the data analyzed here has come from classroom observations and semi-structured interviews carried out with two teachers from the 5th year of elementary school at a public school in Brejo do Cruz - Paraíba. In the theoretical framework, studies of beliefs in the area of language teaching and learning are discussed, based on Richardson (1996), Barcelos (2001, 2006) and Bonfim and Conceição (2009), in addition to some studies in the field of Pedagogical Metalexicography, such as Pontes and Santiago (2009), Coroa (2011), Corrêa (2011) and Bolzan (2012). The analysis indicated that teachers believe in the influence of the context on the meaning of the word searched in the dictionary and that the use of this didactic material helps in the textual production, in addition to the teachers being attentive to compositional aspects of the dictionary. Consequently, the results reveal that the beliefs of the investigated subjects sometimes influence and sometimes go against their pedagogical practices, being also verified the fact that the self-reflection on the teaching experience reinforces the teacher's adherence to a certain evaluative position.

Keywords: Teachers' beliefs. Learner's dictionary. Pedagogical practices.

\section{Introdução}

Este artigo é resultado de uma pesquisa de campo que tratou das crenças de professores de $5^{\circ}$ ano do ensino fundamental acerca do dicionário escolar e do seu uso em sala de aula (BRITO, 2019). O objetivo desse estudo foi analisar como os professores concebiam a obra dicionarista enquanto material didático e de que maneira eles a empregavam e orientavam os estudantes nas atividades propostas em sala de aula e, para tanto, foram coletados dados por meio de questionários fechados, observações de aulas e entrevistas semiestruturadas. Tais instrumentos de coleta possibilitaram a construção de um corpus que foi disponibilizado nos apêndices do trabalho supramencionado.

Entendemos corpus conforme a perspectiva adotada na Linguística de Corpus, no sentido de que esse conceito diz respeito a dados linguísticos compilados em formato eletrônico e que possuem representatividade e tamanho finito e, por sua natureza, podem servir para reuso em outras pesquisas (ALUÍSIO; ALMEIDA, 2006). Isso nos faz pensar que um trabalho científico, por mais que tenha a profundidade de uma tese de doutorado, não consegue esgotar o potencial de análise dos dados coletados em um estudo de campo, sendo academicamente 
relevante o reaproveitamento de um corpus já construído, a fim de suscitar aprofundamentos e outros olhares analíticos, uma vez que, como bem preconiza a máxima de um importante teórico da Linguística Moderna, "é o ponto de vista que cria o objeto" (SAUSSURE, 2004, p. 15). Desse modo, tencionamos, neste artigo, dar continuidade à discussão iniciada em Brito (2019), no que se refere à abordagem contextual de crenças de professores, apresentando um percurso analítico possível para a análise de como se processam, no cotidiano escolar, as possíveis relações entre crença e ação docente, denominadas por Richardson (1996) e outros estudiosos de causa-efeito, hermenêutica e interativa.

No tópico a seguir, discutiremos a ressignificação pela qual passou o conceito de crenças no âmbito da Linguística Aplicada, dando destaque para as contribuições da abordagem contextual, no que tange à compreensão da importância desse construto no processo de ensino-aprendizagem. Depois, sistematizaremos, de forma breve, detalhes quanto à natureza dos dados analisados, aos informantes e ao procedimento analítico assumido no trabalho. Em seguida, analisaremos as crenças dos professores levando em conta não apenas seu dizer, mas especialmente as práticas adotadas por esses sujeitos em sala de aula. Ao final, serão apresentadas as considerações finais e as referências das obras consultadas.

\section{Apontamentos teóricos}

Antropologia, Sociologia, Psicologia, Educação e Filosofia pertencem às ciências humanas. Todas essas disciplinas interessamse, cada uma a seu modo, pelo estudo das crenças dos seres humanos. Contudo, a investigação desse objeto de estudo, no presente trabalho, está inserida no campo da Linguística Aplicada. Nessa área do saber, o termo crenças passou, ao longo do tempo, por uma espécie de ressignificação, à medida que os pesquisadores modificaram as metodologias e estabeleceram um diálogo com diferentes teorias envolvendo a linguagem e o ensino e aprendizagem de línguas, conforme se vê nas pesquisas nacionais mostradas no Quadro 1: 


\section{v. 11 (esp.)}

227-244 ago. 2021
Quadro 1 - O termo crenças em pesquisas da Linguística Aplicada

\begin{tabular}{|c|c|}
\hline Autor & Definição \\
\hline Barcelos (2001) & $\begin{array}{l}\text { "elas podem ser definidas como opiniões } \\
\text { e ideias que alunos (e professores) têm } \\
\text { a respeito dos processos de ensino e } \\
\text { aprendizagem de línguas" (p. 72). }\end{array}$ \\
\hline Madeira (2005) & $\begin{array}{l}\text { "A explicação mais rápida e imediata é } \\
\text { feita através da distinção entre crenças } \\
\text { e conhecimentos. Em termos básicos, } \\
\text { conhecimento é o que se tem como } \\
\text { resultado de pesquisa científica, a partir } \\
\text { de fatos provados empiricamente. } \\
\text { Crenças, por sua vez, são o que se } \\
\text { 'acha' sobre algo - o conhecimento } \\
\text { implícito que se carrega, não calcado na } \\
\text { investigacão sistemática" (p. 19). }\end{array}$ \\
\hline Silva (2005) & $\begin{array}{l}\text { "Ideias ou conjunto de ideias para as } \\
\text { quais apresentamos graus distintos de } \\
\text { adesão (conjecturas, ideias relativamente } \\
\text { estáveis, convicção e fé). As crenças } \\
\text { na teoria de ensino e aprendizagem } \\
\text { de línguas são essas ideias que tanto } \\
\text { alunos, professores e terceiros têm } \\
\text { a respeito dos processos de ensino/ } \\
\text { aprendizagem de línguas e que se (re) } \\
\text { constroem neles mediante as suas próprias } \\
\text { experiências de vida e que se mantêm por } \\
\text { um certo período de tempo" (p.77). }\end{array}$ \\
\hline Barcelos (2006) & $\begin{array}{l}\text { "uma forma de pensamento, como } \\
\text { construções da realidade, maneiras de ver } \\
\text { e perceber o mundo e seus fenômenos, co- } \\
\text { construídas em nossas experiências e } \\
\text { resultantes de um processo interativo de } \\
\text { interpretação e (re)significação. Como } \\
\text { tal, crenças são sociais (mas também } \\
\text { individuais), dinâmicas, contextuais e } \\
\text { paradoxais" (p.18). }\end{array}$ \\
\hline Rocha (2010) & $\begin{array}{l}\text { "as crenças, sob um viés bakhtiniano, } \\
\text { podem ser conceituadas como os } \\
\text { diferentes modos, axiologicamente (leia- } \\
\text { se ideologicamente) constituídos, de } \\
\text { se interpretar o mundo, refletindo-o } \\
\text { e, também, refratando-o. São, } \\
\text { portanto, maneiras discursiva e } \\
\text { socioculturalmente situadas de se } \\
\text { pensar, viver e sentir o mundo, das } \\
\text { quais dialogicamente nos apropriamos } \\
\text { ao participarmos dos infinitos modos } \\
\text { em que se dão as relações humanas. } \\
\text { Pelas crenças, expressamos nossas } \\
\text { valorações ou juízos de valor, quando } \\
\text { enunciamos" (p. 231-232). }\end{array}$ \\
\hline
\end{tabular}

Fonte: Elaborado pelo autor (2020).

Esses são apenas alguns dos trabalhos de pesquisadores brasileiros que contribuíram para a pesquisa e para o refinamento semântico e conceitual do objeto de estudo crenças na área de ensino- 
aprendizagem de línguas. Em Barcelos (2001), vemos que a autora, fazendo um apanhado de pesquisas da área, conceitua crenças de forma bem geral, relacionando-as às "opiniões e ideias" de professores e estudantes no campo educacional. Em oposição, Madeira (2005) restringe esse construto ao "achismo", postura esta que foi bastante comum em alguns estudos da fase inicial e já ultrapassada da investigação das crenças, que as associavam exclusivamente a estereótipos e concepções erradas, como se não fossem um tipo de conhecimento por não resultarem necessariamente de sistematização científica.

Silva (2005), por seu turno, não se filia à abordagem normativa de Madeira (2005) e complementa a conceituação de Barcelos (2001) ao acrescentar à natureza das crenças a dimensão da temporalidade, melhor dizendo, o fato de que elas são relativamente estáveis, pois podem ser (re)construídas nos processos de ensino-aprendizagem de que os sujeitos participam.

Por outro lado, Barcelos (2006) reorienta o conceito proposto em 2001, seguindo, dessa vez, uma linha de raciocínio mais pragmática, considerando que as crenças se constituem não apenas como ideias, mas revelam formas de perceber o mundo e, consequentemente, de construir a realidade. Em consonância com as palavras dessa autora, Rocha (2010) também concebe as crenças como formas de interpretação do mundo reveladas quando enunciamos.

Neste sentido, levando em conta a ressignificação do conceito em debate, ressaltamos que, neste trabalho, adotamos crenças como:

[...] posições valorativas acerca de diferentes aspectos e elementos envolvidos no processo de ensino-aprendizagem [...] construídas e reconstruídas na coletividade ao longo de um emaranhado de vivências. Embora não sejam julgadas sob o status de certas ou erradas, [...] podem configurar-se como adequadas ou inadequadas no que diz respeito a determinadas teorias que contribuem para a organização e a oferta de um ensino de qualidade [...] possuem dupla natureza, uma mais abstrata e outra mais empírica, já que, de um lado, manifestamse discursivamente, e por outro, materializam-se nas tomadas de decisões e ações executadas [...] em sala de aula [...] (BRITO, 2019, p. 37-38).

Esse conceito dialoga com o que é defendido por Silva (2005), Barcelos (2006) e Rocha (2010), dando destaque especial para o fato de que as crenças se manifestam discursivamente, bem como nas ações realizadas em sala de aula. Sendo assim, é possível dizer que a discussão aqui apresentada se insere no paradigma da abordagem contextual de 
v. 11 (esp.)

$227-244$ ago. 2021

investigação das crenças, a qual permite uma análise mais aprofundada de como se estabelecem as relações entre o que os professores pensam sobre o uso do dicionário escolar infantil e a forma como eles abordam esse material didático em suas práticas pedagógicas ${ }^{1}$.

É consenso que as crenças assumem um papel importante na prática pedagógica de professores, já que elas conferem sentido ao trabalho que esses sujeitos planejam e executam em sala de aula, dandolhes segurança no fazer docente e impactando, consequentemente, o processo de ensino e de aprendizagem (SOARES, 2005; BARCELOS, 2006). Desse modo, as pesquisas de crenças de professores têm uma relevância científica e social, pois os seus resultados fornecem contribuições para o entendimento da interferência desse fator na realidade educacional, uma vez que é por meio das crenças que "os professores julgam, decidem, enfim, vivem a sua prática pedagógica" (SOARES, 2005, p. 46).

Para Barcelos (2001), é frequente entre pesquisadores iniciantes nesse campo de investigação a seguinte pergunta: as crenças devem ser analisadas a partir do que professores e estudantes dizem ou inferidas por meio do que eles fazem na prática? A retomada históricotemporal das pesquisas sobre crenças na Linguística Aplicada, em nível internacional e nacional, nos revela as duas possibilidades de estudo. No entanto, "as crenças devem ser inferidas não somente através das afirmações verbais dos participantes, mas também através de suas intenções e ações" (BARCELOS, 2001, p. 74, grifo nosso). Nesse sentido, surgiram diferentes abordagens de pesquisa do construto aqui discutido. As duas primeiras abordagens (normativa e metacognitiva) focalizaram principalmente a natureza linguística e cognitiva das crenças, dentre outras questões. Mais recentemente, as pesquisas têm investigado esse objeto sob uma perspectiva que leva em conta o pressuposto de que o uso da linguagem é uma atividade finalisticamente orientada e voltada para a ação, em outras palavras, a linguagem afeta, modifica, cria a realidade. Daí que as pesquisas mais atuais dessa área de estudo exigem a exploração do contexto específico onde os sujeitos investigados atuam, permitindo assim uma discussão mais aprofundada acerca de experiências e de fatores que influenciam e sustentam as posições valorativas dos informantes, assim como do vínculo que se estabelece entre crença e ação.

\footnotetext{
${ }^{1}$ Não é foco deste trabalho discutir as especificidades das três abordagens de investigação de crenças, normativa, metacognitiva e contextual, já que nossa pesquisa se insere nesta última, que, historicamente, é a mais atual nesse campo de estudos. Para mais detalhes, sugerimos a leitura de Barcelos (2001).
} 
Por seu turno, Bonfim e Conceição (2009), bem como Barcelos (2006), tomando por base Richardson (1996), defendem a existência de três formas básicas de compreensão da relação entre crenças e ação docente: a relação causa-efeito; a relação interativa; e a relação hermenêutica. De antemão, ressaltamos que a observância de cada uma dessas relações amplia o olhar analítico para as crenças e ações apresentadas pelos sujeitos investigados, no caso deste artigo, professores de $5^{\circ}$ ano do ensino fundamental, além de "tornar mais conscientes algumas crenças que interferem nas decisões e atitudes tomadas em sala de aula" (BEJARANO; SOARES, 2008, p. 69).

Na relação causa-efeito, conforme pontuam Bonfim e Conceição (2009), a prática pedagógica é influenciada direta ou indiretamente pelas crenças do professor, fazendo com que ele escolha uma abordagem de ensino que acredita ser mais adequada. Entretanto, como discute Barcelos (2006), é importante ter em mente que crença e ação não se relacionam de forma tão simples quanto parece. Por isso, afirmamos, acompanhando o raciocínio da autora, que se deve atentar para o fato de que existem elementos experienciais e contextuais repercutindo entre a crença do professor e a ação que, com efeito, ele põe em prática em sala de aula.

Na relação interativa, não só as crenças, mas também as experiências e as reflexões sobre ações passadas influenciam no processo de mudança e de formação de novas crenças (BONFIM; CONCEIÇÃO, 2009). Nesse caso, a mudança acontece "quando tomamos consciência do que realmente acreditamos", passamos a questionar a sua coerência no nosso dizer ou no nosso fazer, "e vislumbramos uma possibilidade de pensamento alternativo" (BARCELOS, 2006, p. 26).

No segundo tipo de relação, é possível uma influência mútua entre crença e ação, afinal, "tanto as crenças podem influenciar as ações, quanto as ações podem influenciar crenças" (BARCELOS, 2006, p. 26). Em outras palavras, aquilo que os professores fazem em sala de aula e as decisões que tomam com relação à metodologia empregada diariamente "testam e refinam muitos de seus princípios" (BARCELOS, 2006, p. 27).

Já a terceira relação, a hermenêutica, leva em conta o vínculo entre o contexto, a crença e a ação. Desse modo, há duas possibilidades nessa relação: "a primeira corresponde ao desencontro entre crenças e ações, ou seja, as crenças não correspondem necessariamente à ação; a segunda refere-se à influência dos fatores contextuais" (BARCELOS, 
v. 11 (esp.)

$227-244$ ago. 2021

2006, p. 27). Para a autora, um ponto fundamental a se considerar na relação hermenêutica diz respeito à dissonância, ou seja, à incoerência entre aquilo que os sujeitos investigados dizem e aquilo que eles fazem efetivamente. Nem sempre agimos conforme aquilo que acreditamos, afinal fatores contextuais podem favorecer essa divergência entre discurso e prática de ensino.

A realidade educacional em que o professor está inserido pode inibir, de certa maneira, a adoção de práticas que refletem suas crenças, fazendo com que ele aja condicionado pelo contexto a que está submetido. Para Bonfim e Conceição (2009), levar em conta o contexto, no estudo das crenças de professores, como elemento condicionante das práticas efetivadas nas aulas, possibilita uma análise global e, por conseguinte, menos estereotipada no que se refere às práticas pedagógicas dos professores. Além disso, a abordagem contextual, assumida neste trabalho, pode contribuir para a formação de educadores mais críticos e conscientes, orientados pela atitude de autorreflexão, o que favorece, inclusive, "uma melhor adequação de objetivos, conteúdos e procedimentos em sala de aula [...] redundando em maior eficácia no processo de ensino e aprendizagem de línguas no contexto de ensino brasileiro" (BONFIM; CONCEIÇÃO, 2009, p. 63).

\section{Metodologia}

Como já dissemos, o presente artigo resultou do reuso de parte do corpus de uma pesquisa de campo que investigou crenças de professores de $5^{\circ}$ ano do ensino fundamental sobre o dicionário escolar e sobre o seu uso em sala de aula (BRITO, 2019).

Na referida pesquisa, o corpus foi construído a partir de três instrumentos de coleta de dados. De início, foi aplicado um questionário fechado visando à obtenção de dados pessoais e profissionais dos professores participantes, bem como à aferição de seus posicionamentos com relação a determinadas afirmações sobre o dicionário escolar e seu uso em sala de aula. Essas afirmações foram elaboradas com base em Pontes e Santiago (2009) e em outros trabalhos do campo da Metalexicografia Pedagógica. No segundo momento, ocorreu a observação de cinco (05) aulas de cada um dos informantes, registradas através de notas de campo. Nessa oportunidade, eles foram orientados a desenvolverem aulas envolvendo o uso de dicionários escolares, conforme já realizavam ou levando em conta metodologias que 
considerassem pertinentes. Posteriormente, realizou-se a entrevista individual semiestruturada, com o objetivo de coletar novas informações e de tornar mais claros alguns dados colhidos anteriormente. Por fim, as entrevistas foram transcritas totalmente.

Neste trabalho, revisitamos e analisamos somente dados reunidos a partir de dois instrumentos de coleta citados anteriormente, a observação de aulas e a entrevista individual semiestruturada. Apenas a título de contextualização, gostaríamos de ressaltar que os participantes da pesquisa trabalhavam em turnos diferentes de uma mesma escola da rede municipal de ensino de Brejo do Cruz - Paraíba. No que se refere à faixa etária, havia uma diferença de 20 anos entre os professores investigados: P1 tinha 32 anos e P2, 52. Ambos eram graduados em Pedagogia e, com relação ao tempo de exercício docente nos anos iniciais do ensino fundamental, havia um contraste também expressivo. P2 atuava há 30 anos nesse nível de ensino, já P2 há apenas 2 anos.

É importante frisar que a análise dos dados seguirá uma abordagem qualitativa e interpretativista de trechos de notas de campo sobre aulas observadas, confrontando esse material com informações oriundas de transcrições de entrevistas, de modo a legitimar, assim, a discussão travada no tópico a seguir.

\section{Análise e discussão dos resultados}

O comportamento do ser humano está interligado às suas crenças (BARCELOS, 2006). Dessa maneira, cada ação realizada pelo professor em sala de aula revela uma crença que ele tem acerca de dado elemento do processo de ensino-aprendizagem. No tópico anterior, vimos que o vínculo entre crença e prática pedagógica pode se dar a partir de três maneiras: relação causa-efeito; relação interativa; e relação hermenêutica (RICHARDSON, 1996; BARCELOS, 2006; BONFIM; CONCEIÇÃO, 2009).

Nessa linha de pensamento, objetivando analisar a influência das crenças na prática de ensino dos professores pesquisados, no sentido de explicar como ocorreu a inter-relação entre crenças e ações dos professores, consideramos fundamental cruzar os dados resultantes das observações de aulas com o que P1 e P2 expuseram ao serem entrevistados, uma vez que, nesta etapa de coleta, eles responderam a perguntas que, de alguma forma, estavam relacionadas às experiências pedagógicas observadas. 
v. 11 (esp.)

$227-244$ ago. 2021

Quando comparado a outros textos que circulam socialmente, o dicionário pode representar "um desafio maior, mais sofisticado, especialmente por seu componente de descrição linguística, que nele aparece de forma explícita, desafiando o leitor sem preparo nesse campo de conhecimento" (CORREA, 2011, p. 157). Possivelmente por esse motivo, notamos, em algumas aulas, dificuldades estudantis quanto ao uso proficiente do dicionário. Vejamos, em (01), o relato da forma como P1 agiu diante das dificuldades dos estudantes durante a consulta lexicográfica:

(01) Durante a atividade, P1 auxiliou os alunos, especialmente os que estavam apresentando dificuldades. Para um discente que procurava o significado de "cismar", ele explicou: "tem que ser no ' $\mathrm{C}$ '". Ele próprio indagou para a turma: "professor, é $(\text { sic })^{2}$ os 4 significados? Não, é aquele que se adequar ao contexto do poema" (AULA DE P1, 17/08/17).

Nesse caso, vemos que o professor interviu tentando ajudar os estudantes a realizarem a tarefa, alertando-os, principalmente, para a ordem alfabética das palavras: "[...] Para um discente que procurava o significado de 'cismar', ele explicou: 'tem que ser no 'c')" (AULA DE P1, 17/08/17). Além disso, o professor, de forma dialógica, colocou-se no lugar dos estudantes, externalizou e respondeu à pergunta: "professor, é (sic) os 4 significados? Não, é aquele que se adequar ao contexto do poema". Desse modo, P1 defende a necessidade de que, durante a consulta ao dicionário, o estudante esteja atento para o contexto da palavra consultada. Nesse ponto, seu posicionamento converge com Nascimento (2013, p. 158), para quem é papel do professor orientar o uso do dicionário, de forma que o consulente não leia o verbete pela metade ou selecione "qualquer uma das acepções das palavras".

Ao alertar os estudantes sobre a importância do contexto no qual a palavra pesquisada está inserida, a intervenção de P1 dialoga com o que defende Leffa (2011, p. 127): "é preciso ensinar ao aluno a não se desligar do texto quando vai ao dicionário à procura de uma palavra, retomando a leitura no ponto em que parou do modo mais rápido possível". A prática defendida pelo autor também converge com a ação pedagógica de $\mathrm{P} 2$, conforme expomos em (02):

${ }^{2}$ Ressaltamos que esse extrato da entrevista, no qual se verifica falta de concordância verbal, foi transcrito exatamente conforme a fala do informante. 
(02) Após um tempo, finalizada a consulta, foi solicitado que os alunos lessem o que encontraram na consulta ao dicionário. E assim foi feito. Os alunos liam o significado encontrado, ele pedia para que voltassem o olhar para a parte do texto onde estava a palavra em debate, relia esse trecho e perguntava-lhes se tinha dado para entender melhor o sentido do texto (AULA DE P2, 18/08/17).

Percebemos a preocupação do professor em fazer com que os estudantes voltassem ao texto após a consulta lexicográfica. Desse modo, ele insistia em que os estudantes lessem os significados encontrados, voltassem ao texto em estudo e analisassem se, a partir disso, haviam compreendido melhor o texto. Neste sentido, notamos que ambos os professores buscaram desenvolver nos estudantes a capacidade de integrar o dicionário com o texto trabalhado. Sobre essa questão, é válido lembrar que a construção dos sentidos textuais é resultado da compreensão responsiva do sujeito ao refletir sobre o significado dicionarizado em relação ao texto estudado (LEFFA, 2011).

Neste sentido, podemos dizer que as práticas de P1 e de P2 estão fundamentadas na crença de que o contexto influencia o sentido da palavra pesquisada no dicionário. De fato, essa crença e sua consequente ação em sala de aula encontra respaldo nos estudos e pesquisas da área da Metalexicografia Pedagógica3 ${ }^{3}$ devendo assim ser levada em conta quando se discute o uso proficiente do texto lexicográfico.

A fim de validar a aferição das crenças dos professores a partir de suas ações no ambiente escolar, questionamos os informantes, na etapa da entrevista, se, na realização de uma consulta ao dicionário, havia a necessidade de o consulente não perder de vista o contexto da palavra pesquisada, isto é, voltar seu olhar para o texto em que ela se encontra. Suas respostas podem ser lidas nos excertos (03) e (04):

(03) [...] é muito importante [...] pela questão de, eu posso ter uma palavra, que ela está escrita, mas ela não possa ter o mesmo significado no contexto que ela tá inserida, né?, porque existe o sentido denotativo e o conotativo da palavra, o conotativo seria o mais/denotativo seria o real, e o conotativo seria, é:: a forma de repente que você pudesse, colocar, ou o sentido que queira dar, é:: e isso seria um problema/às vezes/o dicionário ele é direto, mas ele a/pode apresentar vários significados praquela palavra, e qual seria o significado, que mais caberia? Aí ele poderia ver lá no dicionário (P1).

\footnotetext{
${ }^{3}$ Metalexicografia Pedagógica é uma área de estudos da Linguística Aplicada que, em linhas gerais, pesquisa, discute e problematiza a adequação de dicionários ao âmbito educacional, bem como a "formação dos professores para o conhecimento e o aproveitamento pedagógico desse instrumento essencial para o ensino de línguas" (KRIGER; WELKER, 2011, p. 104, grifo nosso).
} 
v. 11 (esp.)

$227-244$ ago. 2021
(04) Sim, muito importante, porque, como a palavra tem vários significados, eu sempre:: deixo isso bem claro pra os alunos, ela tem que tá de acordo com aquela parte do texto, porque ela não tem só um sinônimo. Então ela tem que tá lá com coerência, o que o texto está falando, pra poder eles saber é:: o significado naquele momento (P2).

As falas dos professores confirmam que eles partilham da mesma posição valorativa acerca da influência do contexto no sentido da palavra pesquisada no dicionário. Eles foram unânimes em concordar com a ideia de que o dicionário trabalha com uma multiplicidade de significados de cada entrada nele registrada, cabendo ao consulente refletir sobre qual significado é o mais coerente naquele cenário de dúvida, como bem pontua o informante P2. Sendo assim, é possível afirmar que as práticas de P1 e de P2, expostas anteriormente, são uma consequência, uma espécie de materialização das crenças desses sujeitos. Nas duas práticas, em que P1 solicitava que os estudantes considerassem o contexto do poema e P2 relia determinadas partes textuais onde estavam as palavras pesquisadas no dicionário, efetivou-se a relação de causa-efeito (RICHARDSON, 1996; BARCELOS, 2006), uma vez que, conforme analisado, as intervenções pedagógicas dos professores foram influenciadas direta ou indiretamente pelas suas crenças.

No excerto (05), percebemos que a prática de ensino de P1 aponta para uma crença envolvendo o uso da obra dicionarista para o desenvolvimento da escrita:

(05) O docente iniciou a aula dizendo que iria escrever no quadro três palavras, para que os alunos pesquisassem seus significados em dicionários e, em seguida, escrevessem frases com essas palavras. Dito isto, o professor assim escreveu: denegrir, alameda, diplomata. P1 disse que antes de eles criarem a frase, precisariam saber o sentido da palavra e reiterou: "Leia a palavra, procure entender o que ela significa e, depois, crie a frase" (AULA DE P1, 17/08/17).

Como relatado, o professor escreveu na lousa, em forma de lista, as palavras "denegrir, alameda, diplomata" e orientou que, depois da consulta ao dicionário, os estudantes deveriam criar frases com cada uma dessas unidades lexicais. Vale ressaltar que P1 não apresentou à turma justificativa para a seleção das referidas palavras e, além disso, elas não pertenciam ou dialogavam de alguma forma com os textos trabalhados pelo professor durante o período de observação de aulas.

O dicionário possibilita o acesso a saberes relacionados ao vocabulário de um texto e ao léxico de uma língua. Seu uso em sala 
de aula pode fornecer ao estudante "subsídios e instrumentos para desenvolver a proficiência em leitura e produção de textos (orais e escritos)" (GOMES, 2007, p. 158). Por conseguinte, na tarefa proposta pelo informante $\mathrm{P} 1$, prevaleceu uma perspectiva pedagógica tradicional e descontextualizada, já que ela não se pautou em práticas discursivas que acontecem socialmente. Isso ficou evidente principalmente quando P1 associou o uso do dicionário à elaboração de frases e não de um texto que se configurasse em algum gênero textual.

Nessa perspectiva, Coroa (2011, p. 67) muito contribui na discussão sobre a relevância de se conceber o uso da obra dicionarista como integrante de práticas discursivas, pois assim ela se configurará como um instrumento produtivo na comunicação humana, tornandose "mais um dos elementos simbólicos de que os cidadãos leitores e produtores de textos dispõem para construir, e reconstruir, redes de significação [...]". Neste sentido, o uso constante e consciente desse material didático no ambiente escolar pode fazer com que seu usuário desenvolva proficiência e extraia o máximo de informação que existe no dicionário, contribuindo na aprendizagem linguística do estudante, no que corresponde à aquisição lexical, à leitura e à produção textual, podendo, inclusive, tornar-se "uma ferramenta didático-pedagógica que pode aperfeiçoar as versões de textos e auxiliar nesse processo de descobertas da língua [...]" (BOLZAN, 2012, p. 120).

Na etapa da entrevista, P1 foi indagado se considerava que o dicionário poderia ser usado no trabalho voltado para a produção textual. O excerto (06) mostra como ele se posicionou discursivamente em relação a essa questão:

(06) [...] é:: principalmente nessa ideia/a ideia, você lança um tema e o aluno ele, de repente não sabe, iniciar o seu texto, porque/eu acho o maior, o maior obstáculo pra iniciar pra eles é o início, "que palavrinha eu posso colocar?", porque eles já tinham dimensão dentro das produções de texto, de fazer introdução, desenvolvimento e conclusão, mas como iniciar, eles tavam com um costume ainda de uma produção de texto começar sempre por "era uma vez", que coisas ainda infantil, né?, e eles precisavam, mas qual seria, que palavra poderia ser colocadas?, então, com o dicionário eles poderiam ver ali, de repente, uma palavra que desse um entendimento de dá uma introdução àquele texto. Aí eu falo de introdução, pode/é:: desenvolvimento. Eu, tentei chamar muitas vezes a atenção de não repetir as palavras, é:: ou então colocar aqui "e aí, e aí, e aí", essa repetição, e procurar palavras, conectivos que fizesse/ que não pudesse ser repetidos, e o dicionário seria essencial pra isso $(\mathrm{P} 1)$. 
v. 11 (esp.)

$227-244$ ago. 2021

As palavras de P1 confirmam sua crença sobre o uso do dicionário como ferramenta de auxílio na produção textual, sobretudo no que se refere a evitar a repetição desnecessária de algumas palavras responsáveis pela coesão textual. Em contrapartida, conforme analisado no excerto (05), essa crença materializou-se, na prática pedagógica de $\mathrm{P} 1$, em uma tarefa, a nosso ver, tradicional e descontextualizada, uma vez que esta ficou restrita à pesquisa de palavras aparentemente desvinculadas daquele cenário educacional e à posterior elaboração de frases. Isso evidencia, portanto, uma dissonância entre o que P1 afirmou na entrevista e o que ele propôs em sala de aula. Podemos dizer, então, que essa evidência mostra que houve um "desencontro entre crenças e ações, ou seja, as crenças não correspondem necessariamente à ação" (BARCELOS, 2006, p. 27), o que se enquadra, portanto, na relação hermenêutica (RICHARDSON, 1996; BARCELOS, 2006).

No excerto (07), há mais um relato da prática pedagógica do informante P2:

(07) [...] Um aluno disse-lhe que os dicionários não continham determinada palavra e ele afirmou que era porque, no dicionário, essa palavra em questão estava no masculino. A outros grupos, P2 salientou: "Um dicionário pode ser mais completo do que outro"; "Olhe o Aurélio, o dicionário mais famoso"; "É 'cifradas' e não 'cifrão'. 'Cifrão' é outra coisa"; "Não encontrou nada aí?" (AULA DE P2, 17/08/17).

Ante a dificuldade dos estudantes na consulta lexicográfica, o professor afirmou em sala de aula que uma obra dicionarista pode apresentar mais completude do que outra e, em seguida, orientou-os a pesquisarem no Dicionário Aurélio, pertencente ao acervo bibliográfico da instituição. Dessa vez, a própria prática do professor favoreceu a externalização de uma crença relacionada à diversidade estrutural que a obra dicionarista pode apresentar, o que, inclusive, contraria a ideia equivocada segundo a qual todos os dicionários são iguais, conforme discutem Pontes e Santiago (2009).

$\mathrm{Na}$ entrevista, quando questionado se um dicionário poderia ser mais completo do que outro, P2 disse o seguinte:

(08) Pode, tivemos essa oportunidade de ver lá na sala, uns dicionários com poucas palavras, e outros com mais palavras. Então/a gente comprovou isso, existem alguns mais completos (P2). 
Em (08), vemos que o professor acredita no fato de que os dicionários apresentam diferenças na quantidade de entradas e, para ele, isso comprova a maior completude de uma obra dicionarista em relação a outra. No entanto, gostaríamos de ressaltar que a noção de completude de um dicionário é algo complexo que merece uma reflexão mais apurada, haja vista que o simples fato de esse material didático ser formado por poucas entradas não significa necessariamente que ele é "incompleto" ou inadequado para o uso em sala de aula.

Nesse ponto, é válido trazer à baila a classificação mais recente do PNLD - Dicionários, na qual a quantidade de verbetes é apenas um dos critérios de diferenciação dessas obras em quatro (04) tipos, os quais se destinam a diferentes etapas da educação básica: Dicionários de tipo 1: $1^{\mathrm{O}}$ ano do ensino fundamental; Dicionários de tipo $2: 2^{\circ}$ ao $5^{\circ}$ ano do ensino fundamental; Dicionários de tipo 3: $6^{\circ}$ ao $9^{\circ}$ ano do ensino fundamental; e Dicionários de tipo $4: 1^{\circ}$ ao $3^{\circ}$ ano do ensino médio ${ }^{4}$.

Essa classificação leva em conta não apenas a quantidade de entradas, que evidentemente é menor nos dicionários de tipo 1 e de tipo 2, mas também o fato "de que o consulente do dicionário escolar, ao longo de sua formação na Educação Básica, apresenta distintas necessidades de consulta linguística [...]" (BRANGEL, 2013, p. 220). Desse modo, um dicionário geral não é adequado para estudantes de $1^{\circ}$ a $5^{\circ}$ ano do ensino fundamental, por exemplo, não apenas porque é mais volumoso, mas por apresentar palavras pouco usuais para um estudante em fase inicial de alfabetização ou de consolidação do código escrito. Nesse sentido, a adequabilidade do dicionário escolar ao perfil do estudante refere-se também ao corpus utilizado na produção desse material, sendo comum que os dicionários de tipo 1 e tipo 2 sejam produzidos a partir de obras da literatura infantil, pois espera-se que, assim, esses dicionários sejam mais significativos para o público a que se destinam.

Analisando os dados fornecidos por P2, podemos dizer que a sua crença sobre a existência de dicionários mais completos fundamenta-se em uma postura autorreflexiva em torno de sua prática de ensino. Em (07), vimos que o professor externalizou, em sala de aula, sua crença com o propósito de solucionar a dificuldade de um estudante, já em (08), ele retomou esse momento a fim de justificar seu posicionamento. Neste caso, ocorreu o que alguns pesquisadores denominam de relação

4 Para mais detalhes acerca da classificação dos dicionários escolares, proposta pelo PNLD Dicionários, sugerimos a leitura de Brasil (2012). 
V. 11 (esp.)

$227-244$ ago. 2021

interativa (RICHARDSON, 1996; BARCELOS, 2006), uma vez que não só a posição valorativa do sujeito influenciou a sua prática pedagógica, mas, em contrapartida, a reflexão sobre a ação passada também serviu para reforçar a adesão de P2 à crença analisada.

\section{Conclusão}

Neste trabalho, nosso propósito foi analisar como se relacionam no contexto de sala de aula de $5^{\circ}$ ano do ensino fundamental as crenças e as ações de dois professores quanto ao uso de dicionários escolares. Fundamentados em estudos da área de crenças no ensino e aprendizagem linguística e da Metalexicografia Pedagógica, como Richardson (1996), Barcelos (2001, 2006), Bonfim e Conceição (2009), Coroa (2011), Corrêa (2011) e Bolzan (2012), desenvolvemos uma análise qualitativa e interpretativista de um corpus formado por notas de campo e transcrições de entrevistas.

A análise empreendida aponta que, embora tenha sido verificada uma relação direta entre crença e ação docente, aqui denominada de causa-efeito, também notamos uma divergência envolvendo a posição valorativa e a postura pedagógica assumida em sala de aula (relação hermenêutica), bem como o fato de que não apenas a crença do sujeito professor influencia a sua prática de ensino, mas a reflexão em torno da experiência passada pode servir como mecanismo para justificar e consolidar a sua adesão a determinada crença (relação interativa).

Por fim, parece-nos importante sublinhar a necessidade do desenvolvimento de outras pesquisas nesse campo de estudos, que explorem, por meio de uma abordagem contextual, as categorias conceituais de Richardson (1996) aqui discutidas, focalizando crenças de professores e de estudantes e seu impacto no processo de ensinoaprendizagem das disciplinas que compõem o currículo escolar das diversas etapas educacionais.

\section{Referências}

ALUÍSIO, S. M.; ALMEIDA, G. M. de B. O que é e como se constrói um corpus? Lições aprendidas na compilação de vários corpora para pesquisa linguística. Calidoscópio, São Leopoldo, v. 4, n. 3, p. 156-178, set./dez. 2006.

BARCELOS, A. M. F. Metodologia de pesquisa das crenças sobre aprendizagem de línguas: estado da arte. Revista Brasileira de Linguística Aplicada, Belo Horizonte, v. 1, n. 1, p. 71-92, 2001. 
BARCELOS, A. M. F. Cognição de professores e alunos: tendências recentes na pesquisa de crenças sobre ensino e aprendizagem de línguas. In: BARCELOS, A. M. F.; VIEIRA-ABRAHÃO, M. H. (org.). Crenças e ensino de línguas: foco no professor, no aluno e na formação de professores. Campinas, SP: Pontes Editores, 2006. p. 15-42.

BEJARANO, N. R. R.; SOARES, I. M. F. Crenças dos professores e formação docente. Faced, Salvador, n. 14, p. 55-71, jul./dez. 2008.

BOLZAN, R. M. O uso do dicionário escolar como mediador das práticas discursivas de alunos do ensino fundamental. 2012. $501 \mathrm{f}$. Tese (Doutorado em Estudos da Linguagem) - CLCH, Universidade Estadual de Londrina, Londrina, 2012.

BONFIM, B. S. B.; CONCEIÇÃO, M. P. Crenças de aprendizagem de línguas e a formação reflexiva do professor. Revista Horizontes de Linguística Aplicada, Brasília, v. 8, n. 1, p. 54-67, 2009.

BRANGEL, L. M. Dicionários escolares e ensino de língua portuguesa. Interdisciplinar, São Cristóvão, v. 19, n. 2, p. 217-229, 2013.

BRASIL. Guia de livros didáticos do PNLD 2012 - Dicionários. Brasília: SEF/ MEC, 2012.

BRITO, L. T. A. Crenças de professores do ensino fundamental I sobre o dicionário escolar infantil. 2019. 195 f. Tese (Doutorado em Letras) - DEL, Universidade do Estado do Rio Grande do Norte, Pau dos Ferros, 2019.

COROA, M. L. Para que serve um dicionário? In: CARVALHO, O. L. de S.; BAGNO, M. (org.). Dicionários escolares: políticas, formas \& usos. São Paulo: Parábola Editorial, 2011. p. 61-72.

CORREAA, V. R. Uso de dicionário e ensino de nomenclatura. In: CARVALHO, O. L. de S.; BAGNO, M. (org.). Dicionários escolares: políticas, formas \& usos. São Paulo: Parábola, 2011. p. 155-165.

GOMES, P. V. N. O processo de aquisição lexical na infância e a Metalexicografia do dicionário escolar. 2007. 326 f. Tese (Doutorado em Linguística) Universidade de Brasília, Brasília, 2007.

KRIEGER, M. G.; WELKER, H. A. Questões de Lexicografia Pedagógica. In: XATARA, C.; BEVILACQUA, C. R.; HUMBLÉ, P. R. M. (org.). Dicionários na teoria e na prática: como e para quem são feitos. São Paulo: Parábola Editorial, 2011. p. 103-113.

LEFFA, V. J. Questões de lexicografia pedagógica. In: XATARA, C.; BEVILACQUA, C. R.; HUMBLÉ, P. R. M. (org.). Dicionarios na teoria e na prática: como e para quem são feitos. São Paulo: Parábola Editorial, 2011. p. 123-132.

MADEIRA, F. Crenças de professores de português sobre o papel da gramática no ensino de língua portuguesa. Linguagem e Ensino, Pelotas, v. 8, n. 2, p. $17-38,2005$.

NASCIMENTO, F. I. do. 0 uso do dicionário escolar de língua materna por alunos do $5^{\circ}$ ano de uma escola pública do município de Palhano - CE. 2013. 265 f. Dissertação (Mestrado em Linguística Aplicada) - Centro de 
v. 11 (esp.)

$227-244$ ago. 2021

Humanidades, Universidade Estadual do Ceará, Fortaleza, 2013.

PONTES, A. L.; SANTIAGO, M. S. Crenças de professores sobre o papel do dicionário no ensino de língua portuguesa. In: COSTA DOS SANTOS, F. J. (org.). Letras plurais: crenças e metodologias do ensino de línguas. 1. ed. Rio de Janeiro: CBJE, 2009. p. 105-123.

RICHARDSON, V. The role of attitudes and beliefs in learning to teach. In: J. SIKULA (org.). Handbook of research on teacher education. New York: Macmillan, 1996. p. 102-119.

ROCHA, C. H. Um estudo exploratório sobre o ensino de inglês no fundamental e foco nas crenças dos participantes. In: SILVA, K. A. da (org.). Crenças, discursos e linguagem. Campinas, SP: Pontes Editores, 2010. p. 227-265.

SAUSSURE, F. de. Curso de Linguística Geral. Tradução de Antônio Chelini e Izidoro Blikstein. 26. ed. São Paulo: Pensamento-Cultrix Ltda, 2004.

SILVA, K. A. da. Crenças e aglomerados de crenças de alunos ingressantes em Letras (Inglês). 2005. 217 f. Dissertação (Mestrado em Linguística Aplicada) DLA, Universidade Estadual de Campinas, Campinas, 2005.

SOARES, I. M. F. Se der a gente brinca: crenças das professoras sobre ludicidade e atividades lúdicas. 2005. 249 f. Dissertação (Mestrado em Educação) FACED, Universidade Federal da Bahia, Salvador, 2005. 